\title{
Impacto da absortância e transmitância das fachadas na eficiência energética e conforto térmico para habitação de interesse social
}

Impact of façade absorption and transmittance on energy efficiency and thermal comfort for social housing

Impacto de la absorción y transmitancia de fachadas en la eficiencia energética y el confort térmico para viviendas sociales

CAVALCANTI, Fernando Sá 1

1 Grupo de Estudos em Conforto Ambiental (GECA), Faculdade de Arquitetura e Urbanismo, Universidade Federal de Alagoas, Maceió, Alagoas, Brasil.

fernando.antonio@fau.ufal.br ORCID ID: 0000-0002-0352-6089

Recebido em 14/06/2020 Aceito em 28/08/2020 


\title{
Resumo
}

Este trabalho tem como objetivo apresentar uma discussão acerca da influência que a transmitância térmica e absortância térmica apresentam no conforto térmico e consumo de energia, caso haja a opção pelo uso de ar condicionado para promoção desta sensação em uma habitação de interesse social na cidade de Maceió, Alagoas. Atualmente há uma disseminação do pensamento para a utilização de materiais isolantes em construções de edifícios habitacionais, no entanto para climas quente e úmido, este pensamento é contestado por diversos estudos. A análise aqui realizada ocorreu com o auxílio do software EnergyPlus ${ }^{\circledast}$, versão 9.3 para 42 configurações da edificação, com variação da Transmitância e da absortância térmicas, com o uso de ar condicionado e sem o uso deste dispositivo, para $1 \mathrm{ren} / \mathrm{h}, 5$ $\mathrm{ren} / \mathrm{h}$ e $10 \mathrm{ren} / \mathrm{h}$. Os resultados obtidos quantificam o impacto financeiro no orçamento familiar nesta configuração de habitação, caso ocorra a opção pelo uso de ar condicionado e a influência que as propriedades analisadas apresentam no conforto térmico, com influência maior da absortância em relação à transmitância. Pretende-se então a partir desta pesquisa contribuir para a documentação e conscientização pelo uso de estratégias adequadas ao conforto térmico em condições similares às analisadas.

Palavras-Chave: Transmitância Térmica, Absortância Térmica, Conforto Térmico, Eficiência Energética.

\begin{abstract}
This paper aims to present a discussion about the influence that thermal transmittance and thermal absorptance have on thermal comfort and energy consumption, if there is an option for the use of air conditioning to promote this sensation in a social housing in the city of Maceió, Alagoas. Nowadays, there is a spread of thought for the use of insulating materials in construction of residential buildings, however for hot and humid climates, this thought is contested by several studies. The analysis carried out here took place with the aid of the EnergyPlus ${ }^{\circledR}$ software, version 9.3 for 42 building configurations, with variation of thermal transmittance and absorptance, with the use of air conditioning and without the use of this device, for $1 \mathrm{ren} / \mathrm{h}, 5 \mathrm{ren} / \mathrm{h}$ and $10 \mathrm{ren} / \mathrm{h}$. The results obtained quantify the financial impact on the family budget in this housing configuration, in case the option for the use of air conditioning occurs and the influence that the analyzed properties have on thermal comfort, with a greater influence of absorbance in relation to transmittance. It is intended, then, from this research to contribute to the documentation and awareness of the use of strategies appropriate to thermal comfort in conditions similar to those analyzed.
\end{abstract}

Key-Words: Thermal Transmittance, Thermal Absorptance, Thermal Comfort, Energy Efficiency.

\section{Resumen}

Este artículo tiene como objetivo presentar una discusión sobre la influencia que tienen la transmitancia térmica y la absortancia térmica en el confort térmico y el consumo de energía, si existe una opción para usar el aire acondicionado para promover esta sensación en viviendas sociales en la ciudad de Maceió, Alagoas. Actualmente, existe una gran variedad de ideas para el uso de materiales aislantes en la construcción de edificios residenciales, sin embargo, para climas cálidos y húmedos, este estudio es cuestionado por varios estudios. El análisis realizado aquí ocorrió con la ayuda del software EnergyPlus ${ }^{\circledR}$, versión 9.3 para 42 configuraciones de edificios, con variación de la transmitancia térmica y la absortancia, con el uso de aire acondicionado y sin el uso de este dispositivo, por $1 \mathrm{ren} / \mathrm{h}, 5 \mathrm{ren} / \mathrm{h}$ y $10 \mathrm{ren} / \mathrm{h}$. Los resultados obtenidos cuantifican el impacto financiero en el presupuesto familiar en esta configuración de vivienda, en caso de que se produzca la opción para el uso de aire acondicionado y la influencia que las propiedades analizadas tienen sobre el confort térmico, con una mayor influencia de absorbancia en relación con la transmitancia. Se pretende, entonces, de esta investigación contribuir a la documentación y la conciencia mediante el uso de estrategias apropiadas para el confort térmico en condiciones similares a las analizadas.

Palabras clave: Transmitancia Térmica, Absortancia Térmica, Confort Térmico, Eficiencia Energetica. 


\section{Introdução}

O Brasil possui duas normas que tratam de desempenho térmico de edificações, em 2005 foi criada a primeira Norma Brasileira referente ao desempenho térmico em edificações, a ainda vigente NBR 15220 (ABNT, 2005), que tem como objetivo diminuir o consumo de energia com condicionamento artificial e alcançar maior conforto térmico dos usuários por meios passivos e a NBR 15575, lançada em 2013 e que insere o desempenho térmico como um dos quesitos a serem atendidos para obtenção de um alto nível de desempenho de edificações habitacionais (ABNT, 2013).

A partir da criação destas normas, as construtoras e profissionais de projeto tiveram que atender a requisitos mínimos quanto ao desempenho e conforto térmico (além de outras variáveis para obtenção de um bom desempenho em edificações). Estas normas são diretrizes também para a construção de habitações de interesse social (HIS) que desde a implantação do programa minha casa minha vida (PMCMV) em 2009 tem sido incentivada (BRASIL, 2009), passando por diversas atualizações deste então, até os dias atuais.

No entanto, os resultados deste programa não são satisfatórios quanto à qualidade espacial, uma vez que um mesmo padrão de construção costuma ser reproduzido em larga escala para todo país, sem considerar as características climáticas locais (ALMEIDA, 2014). Alguns autores afirmam ainda que a maioria dos projetos de Habitação de Interesse Social - HIS prioriza somente os custos iniciais, desprezando o desempenho térmico da edificação a longo prazo (KOWALTOWSKI; GRANJA, 2011; TRIANA MONTES, 2016).

Segundo Lamberts e Triana (2007), o desempenho térmico das edificações é influenciado por diversas variáveis, tendo destaque a envoltória e os sistemas construtivos empregados na edificação, além de outros fatores como a orientação solar, área das esquadrias, materiais e cores empregados e o uso ou não de estratégicas bioclimáticas no projeto.

A envoltória é um fator determinante no desempenho térmico e é composta por elementos que estão em contato com o meio externo, sendo divididos em quatro grupos principais: paredes, coberturas, pisos e aberturas. As diferentes características relacionadas aos materiais utilizados, como a transmitância térmica, absortância e capacidade térmica, influenciam significativamente nas características termofísicas da envoltória (FERREIRA et al., 2017).

A transmitância térmica constitui uma das propriedades fundamentais da envoltória para avaliar o desempenho térmico da edificação, por conseguinte, observou-se que as normas vigentes no Brasil sobre desempenho de edificações divergem em relação às exigências relativas à transmitância térmica, sendo a NBR15575 a mais restritiva em quase todos os casos, quando se trata de sistemas de vedação com altas absortâncias, pois esta norma considera parâmetros distintos para revestimentos com cores claras e escuras.

Quanto à absortância térmica, propriedade que informa a porcentagem de radiação absorvida e refletida por uma superfície opaca, as divergências entre as normas são ainda maiores, haja vista que a NBR 15575 admite envoltórias com absortância de 100\%, pois apenas separa as recomendações em 02 grupos: até $60 \%$ e acima de $60 \%$. Esta caracterização simplificada pode comprometer o desempenho térmico de edificações em climas quentes. Já a NBR 15220 estabelece o limite máximo para absortâncias da envoltória ao limitar o fator de ganho solar (FS) das edificações, já que são grandezas diretamente proporcionais.

Com o avanço tecnológico dos materiais de construção, há uma difusão por parte de profissionais de projeto que envoltórias mais isoladas promovem uma maior economia de energia para aquecimento, pois fechamentos com maior resistência térmica reduzem as perdas de calor para o exterior (FRANK, 2005). Este cenário pode ser eficiente no período de inverno, quando a temperatura externa é menor 
que a temperatura interna, porém. Já para verão, para ganhos internos e/ou solares mais altos, existe a hipótese de que fechamentos mais isolados possam provocar elevação da temperatura interna, com consequente aumento do consumo de energia, quando adotado sistema artificial de resfriamento, diminuindo o desempenho térmico desta edificação.

Segundo Triana, Lamberts e Sassi (2015), observa-se que a baixa qualidade da envoltória quanto ao desempenho térmico tem levado os habitantes de HIS a adotarem o uso de condicionamento de ar por meios ativos para a adoção de conforto térmico.

Baseando-se nessa necessidade de averiguar estes novos materiais utilizados no mercado da construção civil e a seu impacto no desempenho térmico das edificações e por consequência, nas vidas dos usuários, esta pesquisa apresenta como objetivo avaliar o desempenho térmico de diferentes sistemas de vedação vertical além do impacto que o uso de ar condicionado apresenta no consumo energético e orçamento destas famílias, observado a viabilidade desses novos materiais e sistemas construtivos, além de sua contribuição para futuras edificações na cidade de Maceió, Alagoas.

\section{Fundamentação}

Diversos estudos vêm sendo realizados com propósito de investigar a necessidade de isolamento da envoltória das edificações (DEVGAN, JAIN e BHATTACHARJEE, 2010; PEDRINI, WESTPHAL e LAMBERTS, 2002), principalmente em climas quentes e úmidos, como é o caso da cidade de Maceió, aqui discutida. Neste tipo de clima, a ventilação natural é a principal recomendação projetual para obtenção de conforto térmico por métodos passivos, no entanto, observa-se uma crescente disseminação do pensamento que o isolamento térmico pode trazer melhorias no desempenho da edificação.

A cidade de Maceió está localizada na Zona Bioclimática 8 de acordo com a classificação da NBR 15.220 (ABNT, 2003) e apresenta segundo Passos (2009), que analisou dados climáticos de uma série histórica em Maceió, temperaturas médias entre $22,9^{\circ} \mathrm{C}$ e $27,9^{\circ} \mathrm{C}$, umidade relativa atingindo os $83,1 \%$ e precipitação de $312,5 \mathrm{~mm}$. A Figura 1 apresenta estes dados, onde é possível observar que $43,5 \%$ das horas durante 0 ano estão em desconforto térmico, devendo ser solucionado preferencialmente por meios passivos no projeto arquitetônico.

Figura 1: Localização da cidade de Maceió, dados climáticos e indicação da porcentagem de horas em conforto e desconforto.
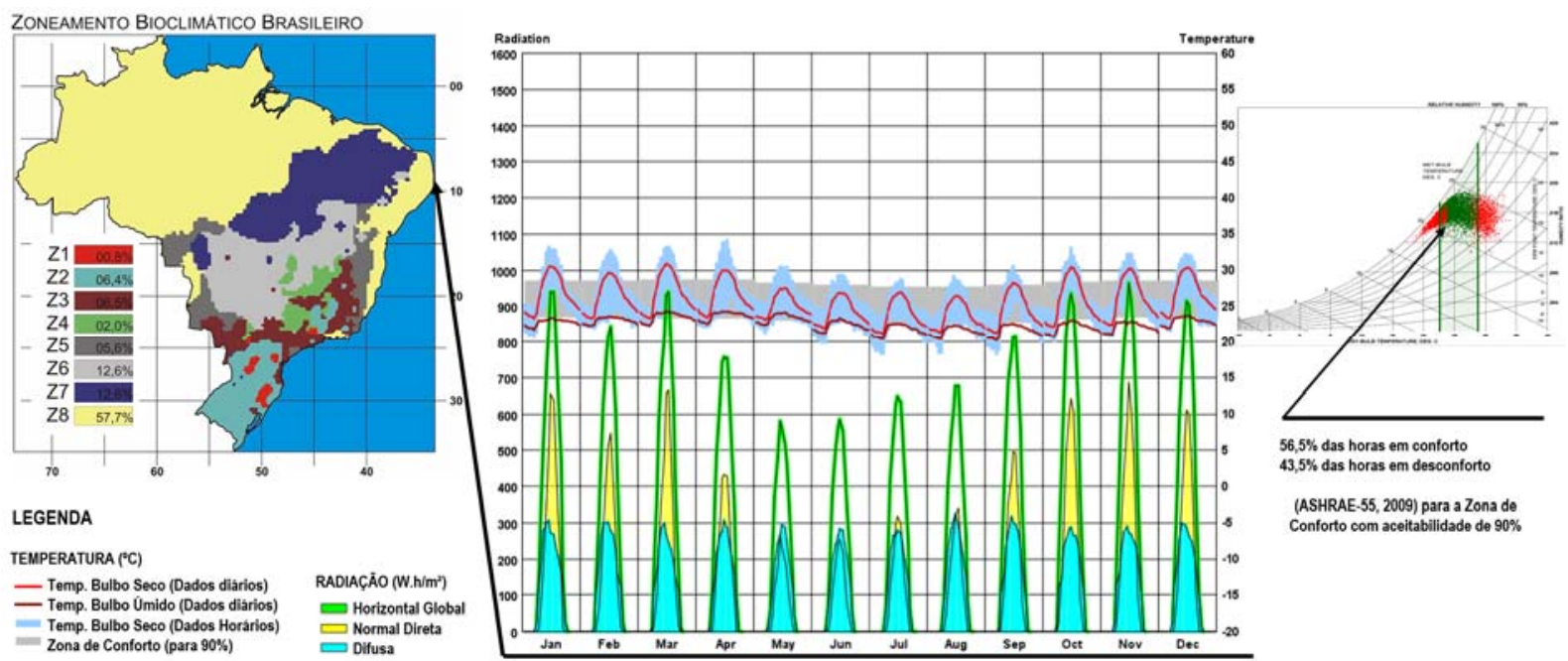

Fonte: Autoria própria, elaborado a partir dos softwares ZBBR (RORIZ, 2004) e Climate Consultant 6.0 (UCLA, 2016). 
As questões relativas ao isolamento térmico da envoltória, mais especificamente dos sistemas de fachadas tem sido avaliadas por diversos pesquisadores. Os estudos de Yik e Wan (2005) apresentaram o histórico do Valor Geral de Transmitância Térmica (VGTT) e as suposições feitas por vários pesquisadores, resumindo as conclusões abordadas por diversos pesquisadores em seus estudos e observaram que este "valor ótimo" nem sempre atende às necessidades climáticas de algumas regiões, principalmente em climas quente e seco e quente e úmido.

Para o clima quente e seco da África do Sul, Masoso e Grobler (2008) identificaram um "ponto de inflexão térmica" para o isolamento térmico e a partir deste ponto, o consumo energético para isolamento térmico passava a ser maior à medida que a transmitância térmica diminui, pois o calor produzido no interior da edificação não era dissipado para o ambiente externo.

Gallardo et al. (2016) afirmam que bons resultados na avaliação de desempenho térmico dependem em grande parte da especificação de materiais e sistemas construtivos. Analisando com base em um clima quente e úmido do Equador, os autores observaram que uma escolha adequada de materiais pode reduzir em até $50 \%$ o número de horas de desconforto térmico de uma habitação, expondo a relevância de análise do tema.

Al-Homoud (2004) estudou, a partir das características térmicas da envoltória de uma edificação, o isolamento e sua influência sobre o desempenho térmico de edifícios em climas quentes. Este trabalho foi realizado a partir de simulações computacionais usando o programa de simulação EnerWin e foi observado que a envoltória pode ajudar a reduzir o sistema de ar condicionado e o consumo de energia, além de ampliar os períodos em conforto térmico enquanto o edifício estiver sendo utilizado.

Em geral, transmitância $(U)$ e resistência térmica $(R)$ são usados nas regulamentações de construção em todo o mundo para prescrever níveis mínimos de isolamento na envoltória de edifícios para que sejam considerados com desempenho termoenergético aceitável. Devido ao seu status legal, essas métricas tornaram-se profundamente incorporadas à indústria da construção e são rotineiramente usadas no projeto de construções.

Os critérios prescritivos baseados em isolamento contidos nos códigos de construção de conservação de energia podem ser analisados criticamente. Os estudos de Lam (et al. 2008) e Radhi (2009) são alguns exemplos para as limitações do papel do isolamento térmico na conservação do consumo de energia para resfriamento a partir do uso de ar condicionados, no contexto de climas tropicais e subtropicais quentes.

Além disso, o isolamento tem sido considerado como indicador do desempenho das edificações. No entanto, analisar apenas esta variável pode não ser o método mais adequado, pois não é o único responsável pelos efeitos da massa térmica e do ganho de calor solar no desempenho térmico (ALTERMAN et al, 2012) e não fornece informações sobre a relação não linear entre o nível de isolamento e o desempenho termoenergético ou a possibilidade de que o desempenho possa realmente reduzir com o aumento do isolamento (MASOSO e GROBLER, 2008).

Observa-se que países pouco industrializados em sua maioria localizados em regiões com clima quente, contrastam-se com os países industrializados (localizados grande parte em climas frios), onde a consciência para buscar um baixo consumo energético das edificações é um pouco maior (KALUA et al, 2014). As estruturas econômicas mais fracas indicam que para os usuários de uma edificação em países subdesenvolvidos, as expectativas em relação ao conforto estão abaixo das obtidas em países industrializados. A maioria dos edifícios residenciais tem funcionamento livre e os usuários acabam sendo induzidos a suportar condições de desconforto durante boa parte do período de ocupação (ASHRAE, 2013).

O desempenho térmico da envoltória da edificação, segundo Kalua (et al, 2014), não inspirou tanto 
interesse nos países menos industrializados, como ocorreu nos países industrializados. O problema permanece abordado de forma vaga nos códigos de edificações e ainda há um certo descaso para com as pesquisas relacionadas ao tema, por parte do poder público. Vários motivos podem ser apresentados para explicar este status quo. Kalua (2016) também aponta alguns, como a baixa vontade política para modernizar radicalmente as legislações urbanas e construtivas em muitos países pouco industrializados. A maioria desses países ainda depende de padrões que antecedem o corpo atual de conhecimento sobre a construção e seu desempenho térmico.

Partindo deste princípio, Roriz (et al, 2009) realizaram uma série de simulações computacionais no cenário brasileiro, para diferentes valores de condutividade térmica e concluíram que o desconforto térmico é diretamente proporcional à resistência térmica $(\mathrm{R})$. Neste estudo, os autores afirmaram que $o$ uso da ventilação natural pode indicar um melhor desempenho da edificação principalmente em climas quentes e úmidos, no entanto, esta pesquisa não incluiu a cidade de Maceió em sua análise.

No Brasil, observa-se que poucas legislações municipais fazem referências às Normas de Desempenho para aprovações de projetos, principalmente de Habitações de Interesse Social, no entanto, há uma preocupação por parte dos órgãos financiadores da construção civil em garantir uma qualidade espacial e desempenho satisfatório, exigindo o cumprimento destas normas brasileiras (RUFINO, 2015).

Pires (2013) alega que sistemas de paredes e coberturas com baixas transmitâncias térmicas e alto atraso térmico são os mais favoráveis para obter níveis satisfatórios de desempenho térmico em climas temperados, como o do Rio Grande do Sul. Ainda, conclui que os tipos de clima do estado se comportam de forma distinta quanto às áreas envidraçadas, sendo que na região da serra gaúcha deve-se empregar áreas menores devido ao período de inverno, e na região metropolitana de Porto Alegre um aumento desta área é favorável ao desempenho.

Em relação ao atendimento de desempenho térmico em todo o Brasil, Moreno, Morais e Souza (2017) observaram que a utilização de materiais cerâmicos apresenta resultados normalmente superiores ao concreto, tanto em paredes quanto em coberturas. Além disso, afirmam que o emprego de cores claras nas superfícies externas é o que se apresenta como melhor alternativa, considerando as oito zonas bioclimáticas (ZB) brasileiras.

Quanto à absortância térmica, propriedade que informa a porcentagem de radiação absorvida e refletida por uma superfície opaca, embora se saiba que as cores são sensações visuais e variam conforme a percepção do observador e que associar esta propriedade com a cor pode ser uma alternativa não confiável (DORNELLES, 2008), esta simplificação é aceita e utilizada por referências normativas nacionais e internacionais, como a American Society of Heating, Refrigerating and Air-conditioning Engineers (ASHRAE, 2011) e NBR 15.220 (ABNT, 2005) e NBR 15.575 (ABNT, 2013).

Ferreira (et al, 2016) após uma análise de a partir de uma edificação padrão em 24 cidades com auxílio do software energyplus, indicaram a necessidade de revisão das Normas Brasileiras de desempenho, principalmente aos valores adotados para a capacidade térmica $(C T)$ das paredes e transmitância $(U)$ e absortância (a) das coberturas no que diz respeito à NBR 15.220 (ABNT, 2003) e Capacidade térmica da paredes e coberturas, além da absortância solar das coberturas na NBR 15.575 (ABNT, 2013).

\section{Metodologia}

Para execução desta análise, visando contemplar os objetivos propostos na pesquisa, foram realizadas simulações computacionais utilizando o software EnergyPlus ${ }^{\circledR}$, Versão 9.3 de uma habitação padrão, com $32,35 \mathrm{~m}^{2}$, pé direito de $2,60 \mathrm{~m}$ e implantada de modo que o dormitório estivesse com a abertura orientada para o oeste (considerada a pior orientação para este ambiente) e assim analisar esta 
edificação em uma situação crítica (Figura 2).

Figura 2: Planta Baixa da Edificação analisada com destaque para a zona analisada (Dormitório).

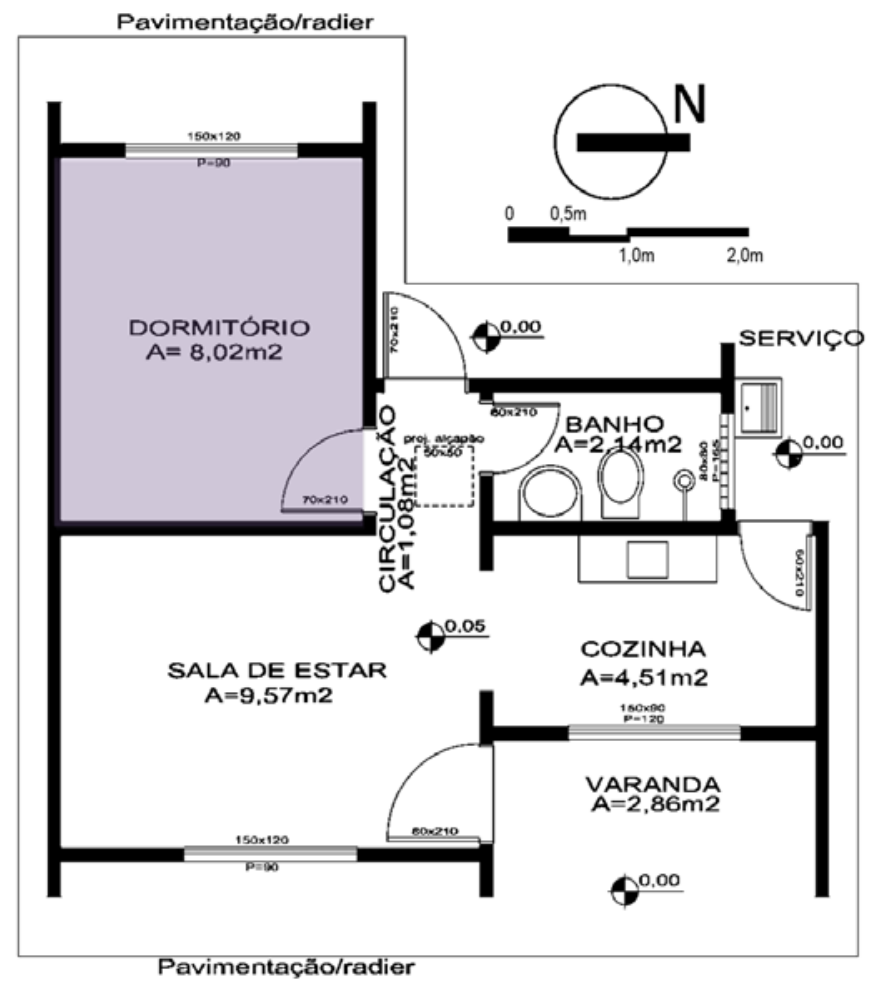

Fonte: Adaptado do Banco de Projetos da Caixa Econômica Federal, (CEF, sd)

\subsection{Caracterização do modelo digital}

E edificação padrão foi modelada com o auxílio do plugin OpenStudio ${ }^{\circledR}$, versão 3.0 para o Sketchup ${ }^{\circledR}$ 2019 com paredes internas com 0,09m de espessura (e), paredes externas compostas por um material teórico de modo a variar sua transmitância térmica $(U)$, forro de gesso e telha cerâmica com inclinação de $25 \%$. Entre o forro e a telha, existe uma câmara de ar, não ventilada e o piso foi considerado de concreto, moldado in loco (Figura 3).

Figura 3: Modelo Digital e características termofísicas dos sistemas construtivos.

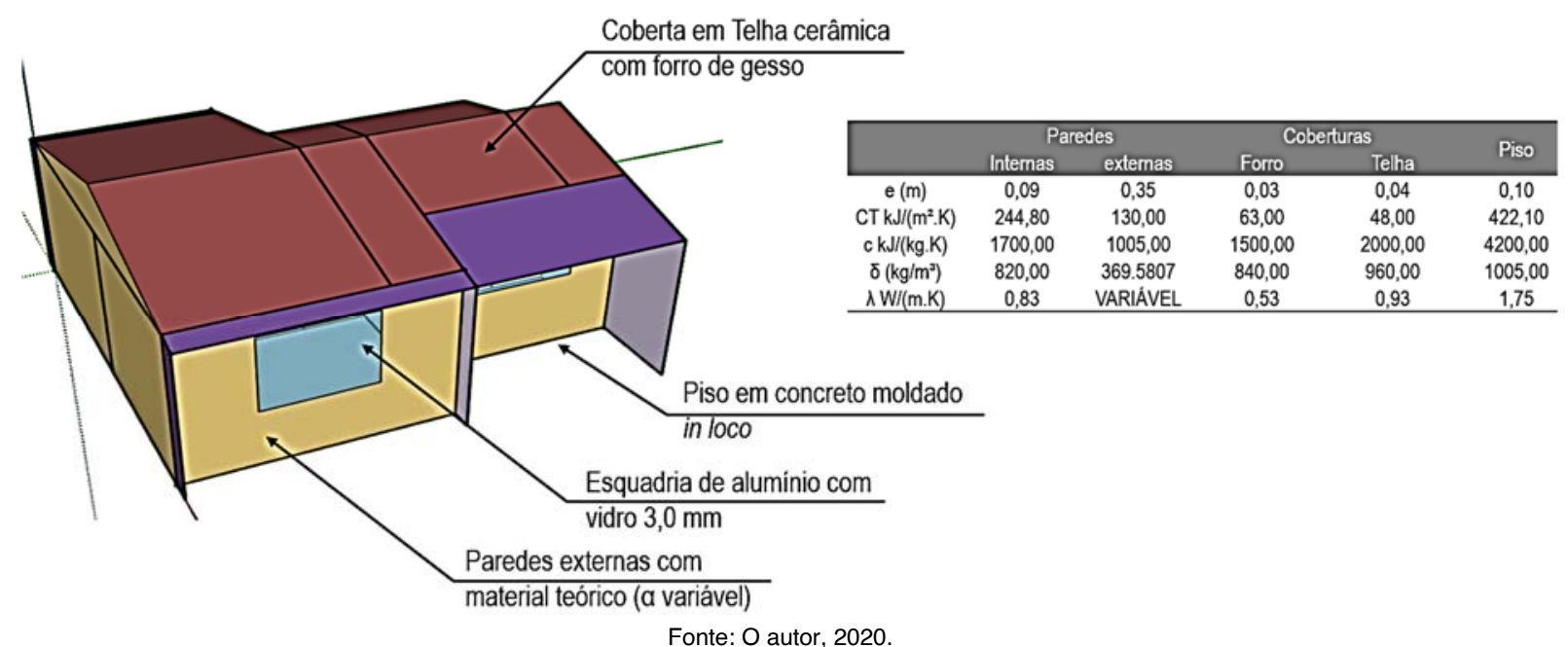


Embora a NBR15575 (ABNT, 2003) solicite ático ventilado na zona bioclimática 8, tem-se observado que esta recomendação não é seguida quando se trata da produção de habitações unifamiliares na cidade de Maceió, que não possui esta exigência em seu código de obras (PMM, 2007).

O valor atribuído para a condutividade térmica $(\lambda)$ das paredes externas foram alterados para cada caso, de modo a manter a espessura deste sistema e alterar o valor de "U". as demais propriedades termofísicas, como capacidade térmica (CT), calor específico (c) e densidade dos materiais foram mantidas constante em todos os modelos e assim foi possível identificar a influência apenas das variáveis consideradas nesta análise para o conforto térmico dos usuários.

A transmitância dos sistemas de vedação externa foi considerada variável, dentro dos parâmetros apresentados na Tabela 1 , entre $1,0 \mathrm{~W} / \mathrm{m}^{2} \mathrm{~K}$ e $4,0 \mathrm{~W} / \mathrm{m}^{2} \mathrm{~K}$, variando apenas a condutividade térmica deste sistema. A absortância destas superfícies também foi considerada variável, com valores de $0.15,0.30$, $0.45,0.60,0.75$ e 0.90 com objetivo de analisar também a influência deste parâmetro no conforto dos usuários.

Tabela 1: Características e propriedades para as paredes externas da edificação.

\begin{tabular}{|c|c|c|c|c|c|c|}
\hline & \multicolumn{5}{|c|}{ Propriedades } \\
\hline & & $\begin{array}{c}\mathrm{e} \\
(\mathrm{m})\end{array}$ & $\begin{array}{c}\mathrm{CT} \\
\mathrm{kJ} /\left(\mathrm{m}^{2} \cdot \mathrm{K}\right)\end{array}$ & $\begin{array}{c}\mathrm{c} \\
\mathrm{kJ} /(\mathrm{kg} \cdot \mathrm{K})\end{array}$ & $\begin{array}{c}\delta \\
\left(\mathrm{kg} / \mathrm{m}^{3}\right)\end{array}$ & $\begin{array}{c}\lambda \\
W /(m \cdot K)\end{array}$ \\
\hline \multirow{7}{*}{ 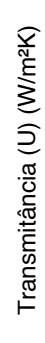 } & 1.00 & 0.35 & 130 & 1005 & 369.58 & 0.52 \\
\hline & 1.50 & 0.35 & 130 & 1005 & 369.58 & 0.695 \\
\hline & 2.00 & 0.35 & 130 & 1005 & 369.58 & 0.87 \\
\hline & 2.50 & 0.35 & 130 & 1005 & 369.58 & 1.045 \\
\hline & 3.00 & 0.35 & 130 & 1005 & 369.58 & 1.22 \\
\hline & 3.50 & 0.35 & 130 & 1005 & 369.58 & 1.395 \\
\hline & 4.00 & 0.35 & 130 & 1005 & 369.58 & 1.57 \\
\hline
\end{tabular}

As esquadrias foram consideradas de correr, com $50 \%$ de sua área total para ventilação natural. A fachada principal da edificação foi orientada para o leste que conforme é possível observar na Figura 4 , recebe a ventilação natural predominante (para Maceió, proveniente do quadrante leste) de forma direta, o dormitório, por sua vez, foi orientado para oeste conforme recomendado pela NBR 15575 (ABNT, 2013) tornando possível analisar a situação de implantação menos favorável para esta tipologia.

Figura 4: Dados da ventilação natural na cidade de Maceió, Alagoas.

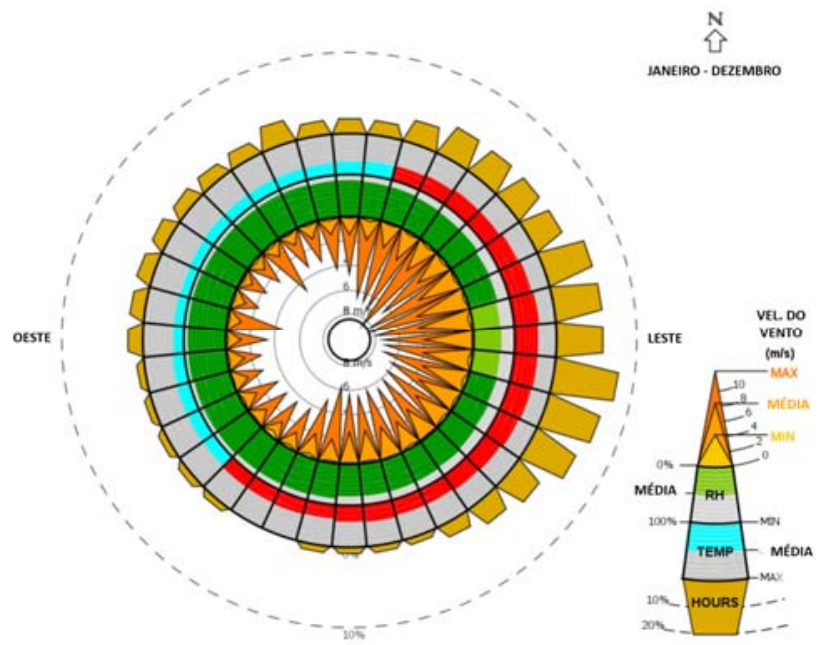

Fonte: Autoria própria, elaborado a partir do software Climate Consultant 6.0 (UCLA, 2016) 
Foram realizadas simulações considerando uma troca de ar no interior desta edificação com valores de $1 \mathrm{ren} / \mathrm{h}$ (portas e janelas fechadas, considerando apenas a infiltração do ar), $5 \mathrm{ren} / \mathrm{h}$ e $10 \mathrm{ren} / \mathrm{h}$ com o objetivo de verificar o uso da edificação com e sem ar condicionado e a possibilidade de inserção da ventilação natural no padrão de ocupação destes espaços. Para os modelos com $01 \mathrm{ren} / \mathrm{h}$, foram simulados modelos com e sem ar condicionado, para avaliar também a diferença total do consumo de energia pela edificação padrão.

\subsection{Descrição do processo de simulações}

Existe uma crítica frequente quanto ao o fato de a NBR 15575 (ABNT, 2013) não considerar a simulação anual horária pois este tipo de simulação poderia representar melhor o desempenho do edifício, indicando os graus-hora de desconforto por calor e/ou frio ao longo do ano com base em recomendações já estabelecidas na literatura (SORGATO; MELO; LAMBERTS, 2013, CHVATAL, 2014), assim, para este trabalho, foram realizadas simulações horárias para um ano típico.

Para as simulações, foi avaliado o período de um ano, baseado no arquivo climático (extensão .epw) para a cidade de Maceió-AL, disponível no sítio do Laboratório de Eficiência Energética das Edificações (LabEEE) por ser considerado mais próximo da realidade local. Este arquivo foi elaborado a partir da base de dados do INMET e está disponível como parte de uma base de dados de 411 municípios brasileiros (RORIZ, 2012).

O contato entre a edificação e o solo foi modelado com o auxílio do Ground Dommain: Slab (Figura 5).

Figura 5: Modelagem do Ground Domain no EnergyPlus ${ }^{\circledR}$.

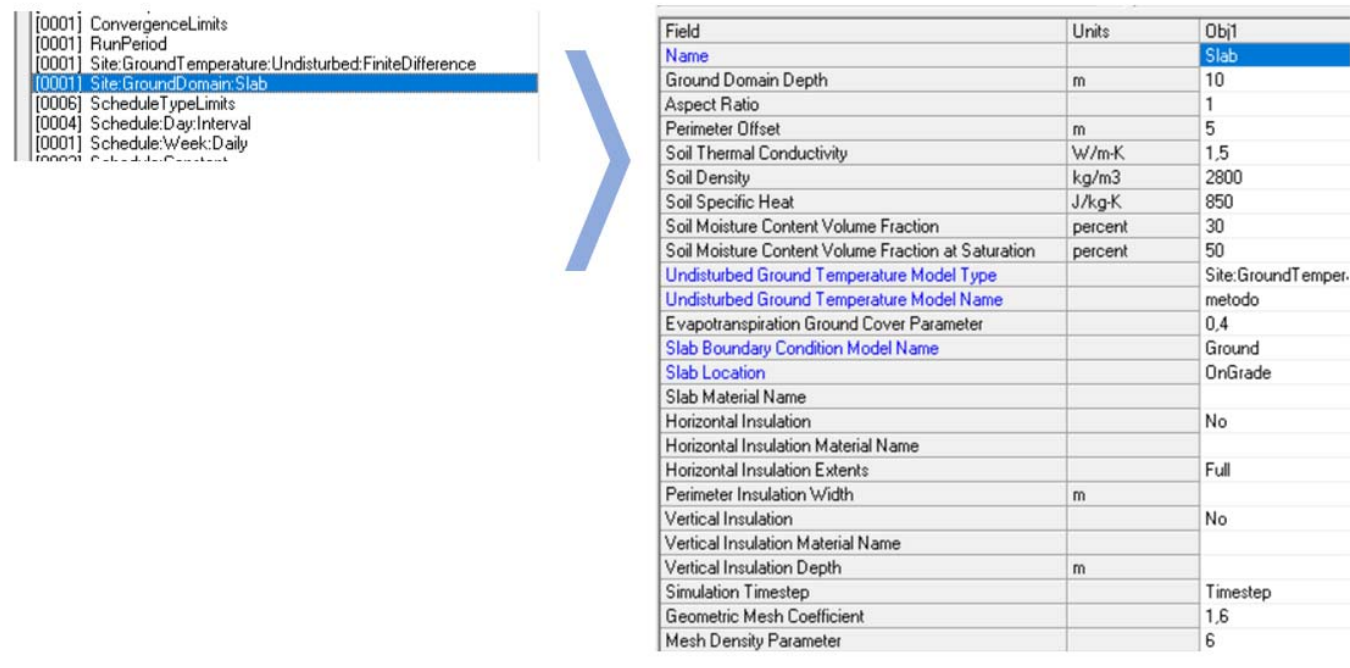

Fonte: Adaptado de EnergyPlus ${ }^{\circledR}, 2020$

A ocupação e as cargas térmicas internas no dormitório foram consideradas as seguintes: 02 pessoas com permanência entre as 21 horas e 06h 59min, com atividade metabólica de $45 \mathrm{~W} /$ pessoa o que representa uma atividade de repouso, além de iluminação de $5,0 \mathrm{~W} / \mathrm{m}^{2}$ no período de permanência dos usuários neste ambiente. Para cozinha/sala de estar conjugada, utilizou-se a ocupação de $14 \mathrm{~h}$ às $21 \mathrm{~h}$, com iluminação ligada das $17 \mathrm{~h}$ às $21 \mathrm{~h}$, atividade metabólica de $60 \mathrm{~W}$ e densidade de potência de $6 \mathrm{~W} / \mathrm{m}^{2}$ (INMETRO, 2012).

As simulações computacionais foram realizadas com dados de saída que quantificaram o consumo de energia elétrica dos sistemas de iluminação artificial e condicionamento de ar, os ganhos de calor interno 
advindos de sistemas de iluminação artificial e refrigeração e por meio dos fechamentos transparentes e as temperaturas do ar no interior dos ambientes.

Embora o modelo base represente uma habitação de interesse social (HIS), observa-se em muitos casos que o uso de ar condicionado é uma opção recorrente para redução do desconforto térmico nestas habitações, elevando os custos com o consumo de energia elétrica de uma parcela da população que possui necessidades diversas, a partir desta constatação, foi considerado um ar condicionado que permanece ligado apenas no período de ocupação e sua configuração encontra-se apresentada na Figura 6.

Figura 6: Modelagem do Ar Condicionado (split) para o dormitório no EnergyPlus ${ }^{\circledR}$.

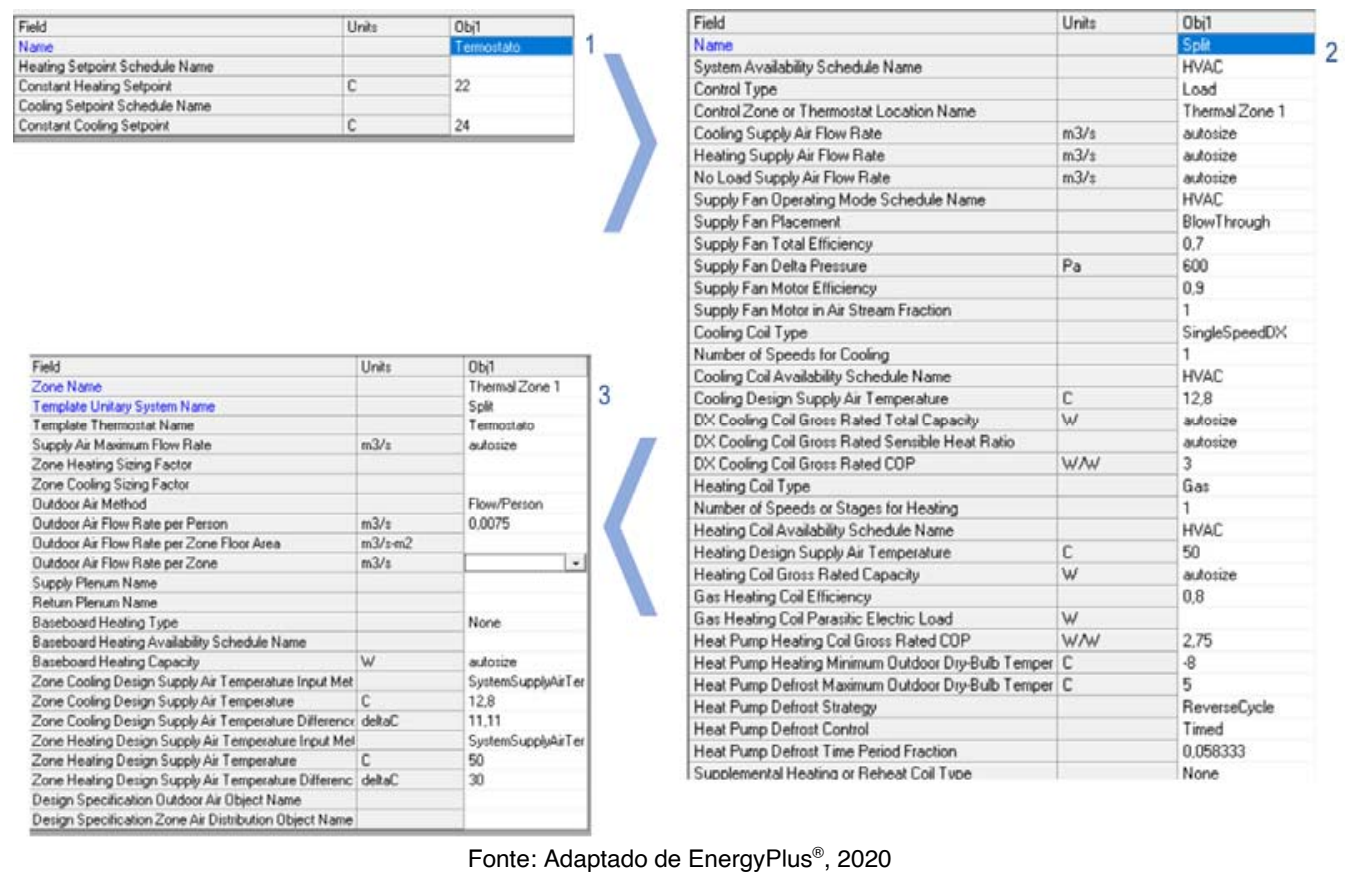

Foram realizadas 42 simulações para cada situação considerada neste trabalho ( 1 ren $/ \mathrm{h}$ - com e sem ar condicionado, 5 ren $/ \mathrm{h}$ e $10 \mathrm{ren} / \mathrm{h}$ ) gerando um total de 168 simulações, garantindo uma base de dados satisfatória para esta análise.

As características da envoltória foram mantidas as mesmas para o modelo com e sem o uso de ar condicionado com o objetivo de identificar a influência da transmitância e absortância, quando analisadas de forma paramétrica no conforto térmico, auxiliando na decisão projetual e tornando possível optar pela estratégia que promova maior impacto no resultado associado ao custo de sua implantação.

Para os dados de saída, foram coletados para o modelo com ar condicionado, o consumo de energia e para os modelos sem ar condicionado a temperatura interna, além da temperatura externa de acordo com o arquivo climático utilizado.

\subsection{Análise dos resultados}

A análise dos resultados ocorreu em duas etapas: inicialmente verificou-se o consumo energético do ar condicionado proposto para avaliar o impacto deste dispositivo de controle da temperatura interna no orçamento familiar e assim comparar com esta edificação quando utilizado apenas meios passivos para promoção de conforto térmico. 
Para a avaliação do custo do consumo de Energia elétrica do sistema de ar condicionado, foi considerado o valor da tarifa energética disponibilizada pela Agência Reguladora de Serviços Públicos do Estado de Alagoas (ARSAL), conforma apresentado na Figura 7, sem considerar as bandeiras amarelas e vermelhas (com incidência de taxas) para verificar o melhor cenário e o menor gasto com este dispositivo na edificação.

Figura 7: Indicação do Custo do KWh em Alagoas.

\begin{tabular}{|c|c|c|c|c|}
\hline \multicolumn{5}{|c|}{ Tarifas Convencionais (Resolução ANEEL N 539 de 21/08/2007) Aplicação:28/08/2007 } \\
\hline & $\begin{array}{l}\text { BAIXA TENSÃO RESIDENCIAL } \\
\text { Faixas de Consumo }\end{array}$ & $\begin{array}{l}\text { CONSUMO } \\
\text { R\$/kWh }\end{array}$ & \multicolumn{2}{|c|}{$\begin{array}{c}\text { TAXA MÍNIMA } \\
\text { RESIDENCIAL } \\
\text { Baixa Renda } 30 \mathrm{kWh}\end{array}$} \\
\hline \multicolumn{2}{|r|}{ B1 - Residencial BAIXA RENDA até 30kWh } & 0,11896 & \multirow{2}{*}{\multicolumn{2}{|c|}{$\mathrm{R} \$ 3,57$}} \\
\hline \multicolumn{2}{|r|}{ B1 - Residencial BAIXA RENDA 31 a 80 kWh } & 0,20392 & & \\
\hline \multicolumn{2}{|r|}{ B1 - Residencial BAIXA RENDA 101 a 140 kWh } & 0,20514 & \multicolumn{2}{|c|}{$\begin{array}{l}\text { TAXA MINIMA } \\
\text { RESIDENCIAL }\end{array}$} \\
\hline \multicolumn{2}{|r|}{ B1 - Residencial BAIXA RENDA 101 a 140 kWh } & 0,30767 & $30 \mathrm{kWh}$ & $100 \mathrm{kWh}$ \\
\hline \multirow[t]{2}{*}{ B1 } & $\begin{array}{l}\text { Residencial BAIXA RENDA superior ao limite regional de } \\
\text { 140KWhB1 }\end{array}$ & 0,3419 & \multirow[t]{2}{*}{$\mathrm{R} \$ 10,26$} & \multirow[t]{2}{*}{$\mathrm{R} \$ 41,19$} \\
\hline & Residencial & & & \\
\hline \multicolumn{5}{|c|}{ Fonte: Adaptado de (ARSAL, sd) } \\
\hline
\end{tabular}

Em seguida foi realizada a análise do conforto térmico, que ocorreu a partir dos requisitos adequados de conforto indicados pela ASHRAE 55 (2013). Para avaliar os níveis de conforto térmico resultantes de cada alternativa, adotou-se os intervalos confortáveis de temperatura estabelecidos na Norma ASHRAE 55-2013 para ambientes naturalmente ventilados (Equação 1, ASHRAE 2013). Importante virtude dessa norma é seu caráter adaptativo, ou seja, o reconhecimento de que populações aclimatadas em regiões quentes preferem temperaturas mais altas que as preferidas pelos habitantes de zonas frias, e viceversa.

$T_{n}=17,9+0,31 . T E_{m e d}$

Onde:

$\boldsymbol{T}_{n}=$ Temperatura operativa interna ideal, ou de "neutralidade térmica" $\left({ }^{\circ} \mathrm{C}\right)$.

$\boldsymbol{T} \boldsymbol{E}_{\text {med }}=$ Média mensal da temperatura do ar exterior $\left({ }^{\circ} \mathrm{C}\right)$

Sendo a equação 1 válida para $\mathbf{T E}_{\text {med }}$ entre 10.0 e $33.5^{\circ} \mathrm{C}$. De acordo com a ASHRAE 55 (2013), para espaços naturalmente condicionados faz-se uso do método adaptativo. A teoria adaptativa determina que ao ocorrer mudanças de temperatura que causem desconforto, as pessoas reagem de forma a tentar fazer com que seu corpo retorne ao estado de conforto (ASHRAE 55, 2013).

Os níveis de desconforto térmico foram quantificados em horas de desconforto por calor e por frio. Cada hora de desconforto corresponde ao período determinado pela temperatura do ar interna quando esta é menor que o limite inferior (frio) ou ultrapassa o superior (calor), em ao menos $1^{\circ} \mathrm{C}$.

A partir deste valor, utilizou-se um total de 8760 horas/ano para obter a porcentagem (\%) de horas em que a edificação proporcionava um desconforto térmico aos usuários e assim verificar de forma prática o desempenho desta edificação nas condições analisadas.

\section{Resultados e discussões}

Os resultados obtidos estão apresentados a seguir e foram divididos em duas partes: inicialmente serão 
apresentados e discutidos os resultados acerca da viabilidade do uso de ar condicionado na edificação padrão e em seguida a influência da Transmitância e da Absortância Térmicas a partir da opção em utilizar sistema de ventilação natural (para 5 e 10 renovações de ar por hora) ou apenas com a infiltração pelas frestas das aberturas.

\subsection{Impacto do consumo do ar condicionado}

No que se refere à viabilidade do uso de ar condicionado no dormitório da edificação analisada, vale ressaltar que no caso da cidade de Maceió, em decorrência das suas características climáticas, apenas o uso do ar condicionado para resfriamento foi necessário. Observa-se então a partir destes dados que de um modo geral, a absortância da superfície externa influencia de forma negativa no consumo do ar condicionado, pois à medida em que esta variável aumenta, ocorre um aumento da temperatura superficial externa da edificação e em consequência deste fenômeno, o sistema de condicionamento de ar utiliza uma quantidade maior de energia para resfriar o ambiente durante todo o ano, no entanto, ao observar a transmitância térmica da envoltória, observa-se que à medida em que o sistema se torna mais isolante termicamente, o comportamento do consumo energético varia ao longo do ano.

A Figura 8 apresenta os dados de consumo mensal para os modelos com absortância de 0,15 e 0,90 (valores extremos desta análise) e é possível identificar a partir destes dados que a variação da transmitância térmica indicam que sistemas com maior isolamento térmico $\left(U=1,0 \mathrm{~W} / \mathrm{m}^{2} \mathrm{~K}\right)$ apresentam um menor consumo energético por este dispositivo, quando associado a uma alta absortância, já para valores com baixa absortância térmica, este comportamento, embora verificado no período quente (outubro a março) não ocorre no período chuvoso (abril a setembro) quando as temperaturas externas são mais baixas para a cidade de Maceió.

Figura 8: Consumo mensal para o sistema de ar condicionado nos modelos com absortância de 0,15 e 0,90.

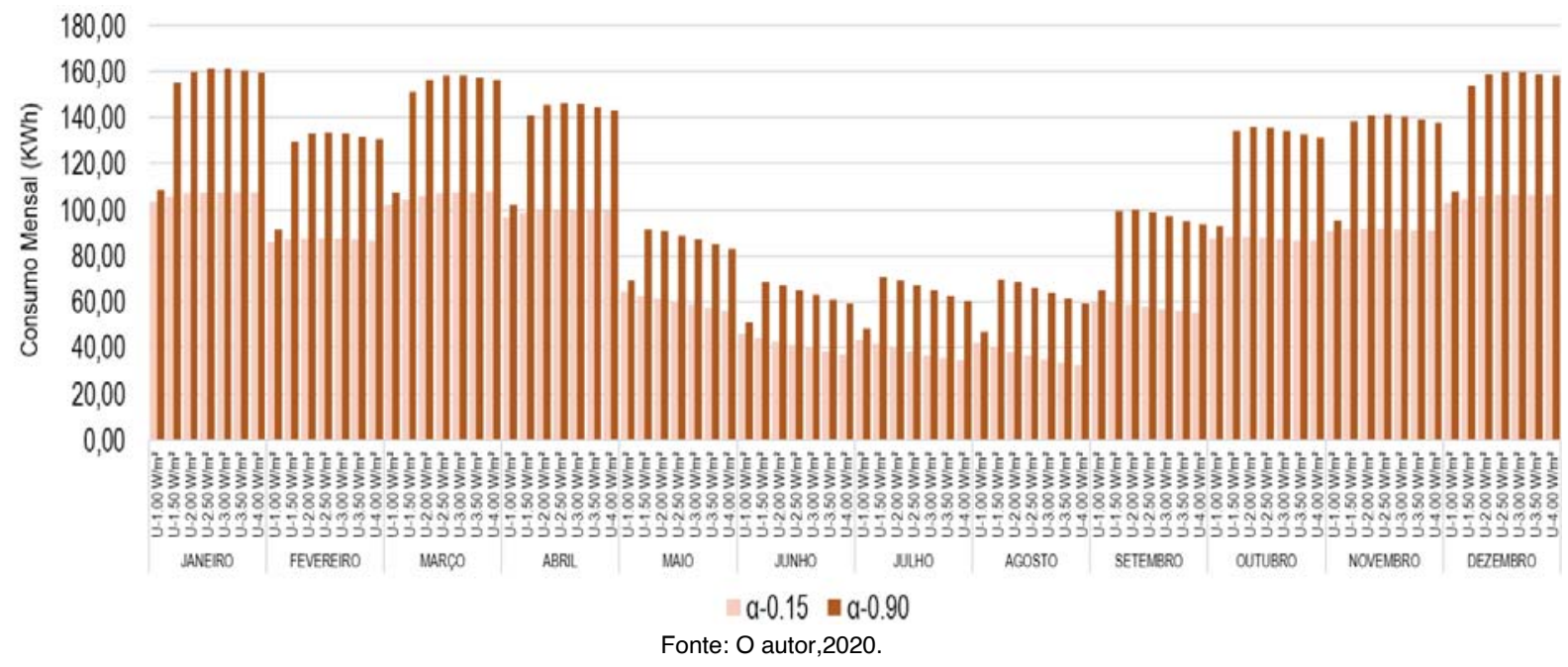

Neste período chuvoso, uma alta transmitância térmica proporciona menor consumo energético por este sistema. Embora com uma diferença pequena entre os modelos com alta transmitância térmica e os modelos com baixa transmitância térmica. Quando se analisa o consumo anual do sistema de condicionamento de ar para cada modelo considerado, é possível mensurar a partir deste consumo acumulado a viabilidade de uso de um sistema de ar condicionado para esta tipologia de edificação e seu impacto no orçamento familiar dos moradores.

Observa-se então, a partir das Figuras 9 e 10, o comportamento desta variável em função da transmitância e da absortância térmicas e nota-se que no caso da alteração da transmitância térmica 
(Figura 9.b), o consumo de energia apresenta um comportamento com tendência parabólica (Figura 10), indicando que sistemas muito isolados e sistemas pouco isolados termicamente, com as mesmas absortâncias, apresentam desempenho similar para a cidade de Maceió, o que não justifica o excesso de isolamento térmico para uso de ar condicionado, embora a NBR 15220 recomende um valor para transmitância menor que $3,6 \mathrm{~W} / \mathrm{m}^{2} \mathrm{~K}$, o maior consumo energético ocorre em aproximadamente valores de $\mathrm{U}=2,5 \mathrm{~W} / \mathrm{m}^{2} \mathrm{~K}$.

Figura 9: Consumo energético anual para o sistema de ar condicionado em função da absortância (a) e transmitância (b).
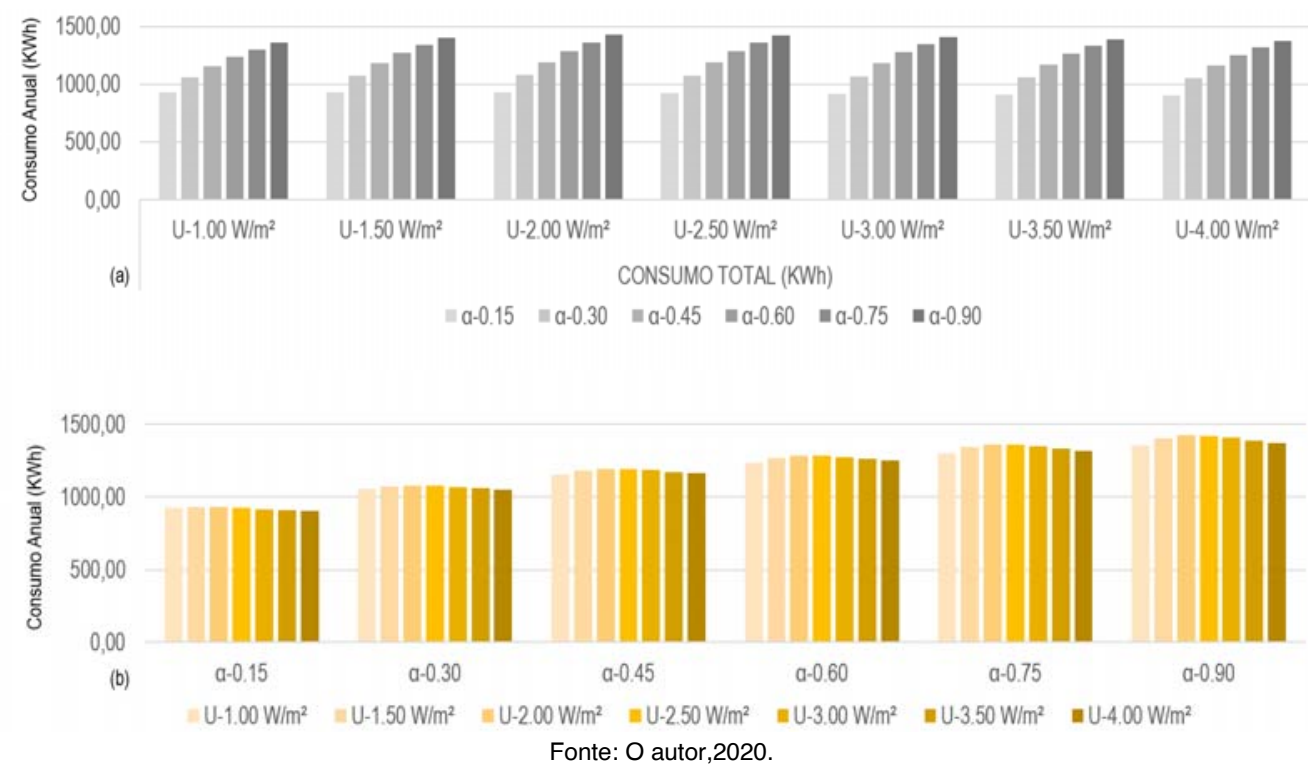

Figura 10: Comportamento das linhas de consumo energético em função da transmitância (à esquerda, em azul) e absortância (à direita, em vermelho).
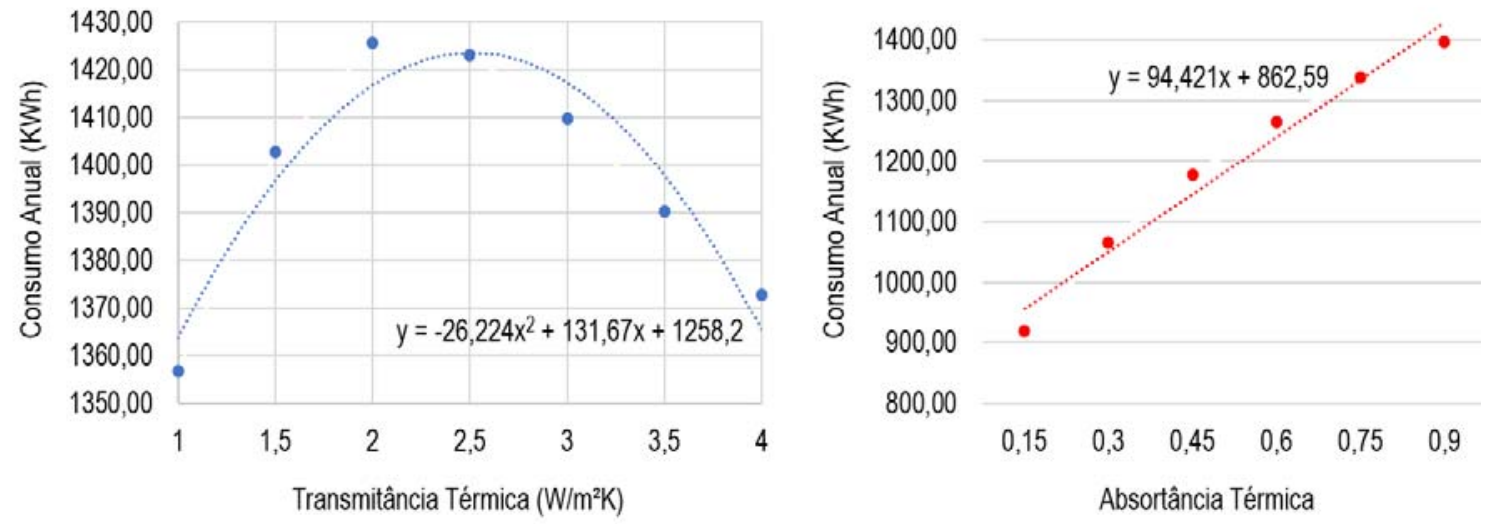

Fonte: O autor,2020.

Este fato pode ser compreendido a partir da facilidade ou dificuldade de trocas térmicas entre o interior e exterior. Sistemas de fachada com alto isolamento térmico (baixa transmitância) impedem que o calor absorvido pela superfície externa cause influência na temperatura interna, enquanto sistemas pouco isolantes (alta transmitância térmica) possibilitam que as trocas térmicas ocorram no interior do sistema, pois no caso da cidade de Maceió, não há uma alta amplitude térmica ao longo do dia em virtude de suas características climáticas (quente e úmido).

Pode-se afirmar também que a absortância apresenta maior influência nesta variável que a transmitância, no caso da cidade de Maceió, com comportamento linear crescente e por ser uma 
alternativa mais barata ao isolamento térmico, apresenta-se como uma boa alternativa para esta tipologia de edificação.

Ao analisar o custo da tarifa energética da cidade de Maceió, foi considerado o consumo anual da edificação e o valor de $R \$ 0,3419$ para cada $K W h$ e é possível observar estes dados na Tabela 2 e afirmar que o custo anual da inserção de um sistema de ar condicionado conforme utilizado nesta análise custa entre $R \$ 307,98$ e $R \$ 487,39$ (valores em destaque). Estas quantias são consideradas elevadas para uma população de baixa renda, pois comprometem no orçamento familiar para este período, no mínimo, um valor entre $29,47 \%$ e $46,64 \%$ do salário mínimo brasileiro (atualmente adotado $R \$ 1045,00$ ).

Tabela 2: Consumo mensal do sistema de Ar condicionado (KWh) para os modelos considerados na análise.

\begin{tabular}{|c|c|c|c|c|c|c|c|}
\hline & & $a-0.15$ & $a-0.30$ & $a-0.45$ & $a-0.60$ & $a-0.75$ & $a-0.90$ \\
\hline \multirow{7}{*}{ 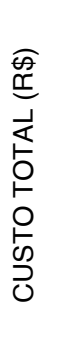 } & $\mathrm{U}-1.00 \mathrm{~W} / \mathrm{m}^{2}$ & 316.47 & 360.92 & 394.49 & 421.92 & 444.67 & 463.82 \\
\hline & $\mathrm{U}-1.50 \mathrm{~W} / \mathrm{m}^{2}$ & 317.45 & 366.22 & 403.87 & 434.26 & 458.96 & 479.62 \\
\hline & $\mathrm{U}-2.00 \mathrm{~W} / \mathrm{m}^{2}$ & 316.88 & 368.01 & 407.55 & 438.38 & 465.68 & 487.39 \\
\hline & $\mathrm{U}-2.50 \mathrm{~W} / \mathrm{m}^{2}$ & 315.20 & 367.19 & 407.29 & 439.04 & 465.06 & 486.50 \\
\hline & $\mathrm{U}-3.00 \mathrm{~W} / \mathrm{m}^{2}$ & 312.87 & 364.79 & 404.58 & 435.73 & 461.21 & 482.00 \\
\hline & $\mathrm{U}-3.50 \mathrm{~W} / \mathrm{m}^{2}$ & 310.19 & 361.46 & 400.49 & 431.06 & 455.45 & 475.33 \\
\hline & $\mathrm{U}-4.00 \mathrm{~W} / \mathrm{m}^{2}$ & 307.98 & 358.67 & 396.97 & 426.83 & 450.40 & 469.35 \\
\hline
\end{tabular}

Fonte: $\mathrm{O}$ autor.

\subsection{Influência no Conforto Térmico}

No que se refere ao conforto térmico dos usuários, foram considerados os modelos com 1,5 e 10 renovações de ar por hora, sem o uso de ar condicionado. A Figura 11 apresenta o comportamento da temperatura para o modelo com Transmitância $U=4,0 \mathrm{~W} / \mathrm{m}^{2} \mathrm{~K}$ e Absortância de 0,15 para as três considerações de renovações do ar, inseridos na zona de conforto proposta pela ASHRAE-55 (ASHRE, 2013), sendo possível observar o desconforto por calor e por frio (este último observado apenas para 10 ren/h) provocado por esta configuração. 
Figura 11: Limites da Zona de Conforto e Temperaturas Internas para 1 ren/h, 5 ren/h e 10 ren/h.
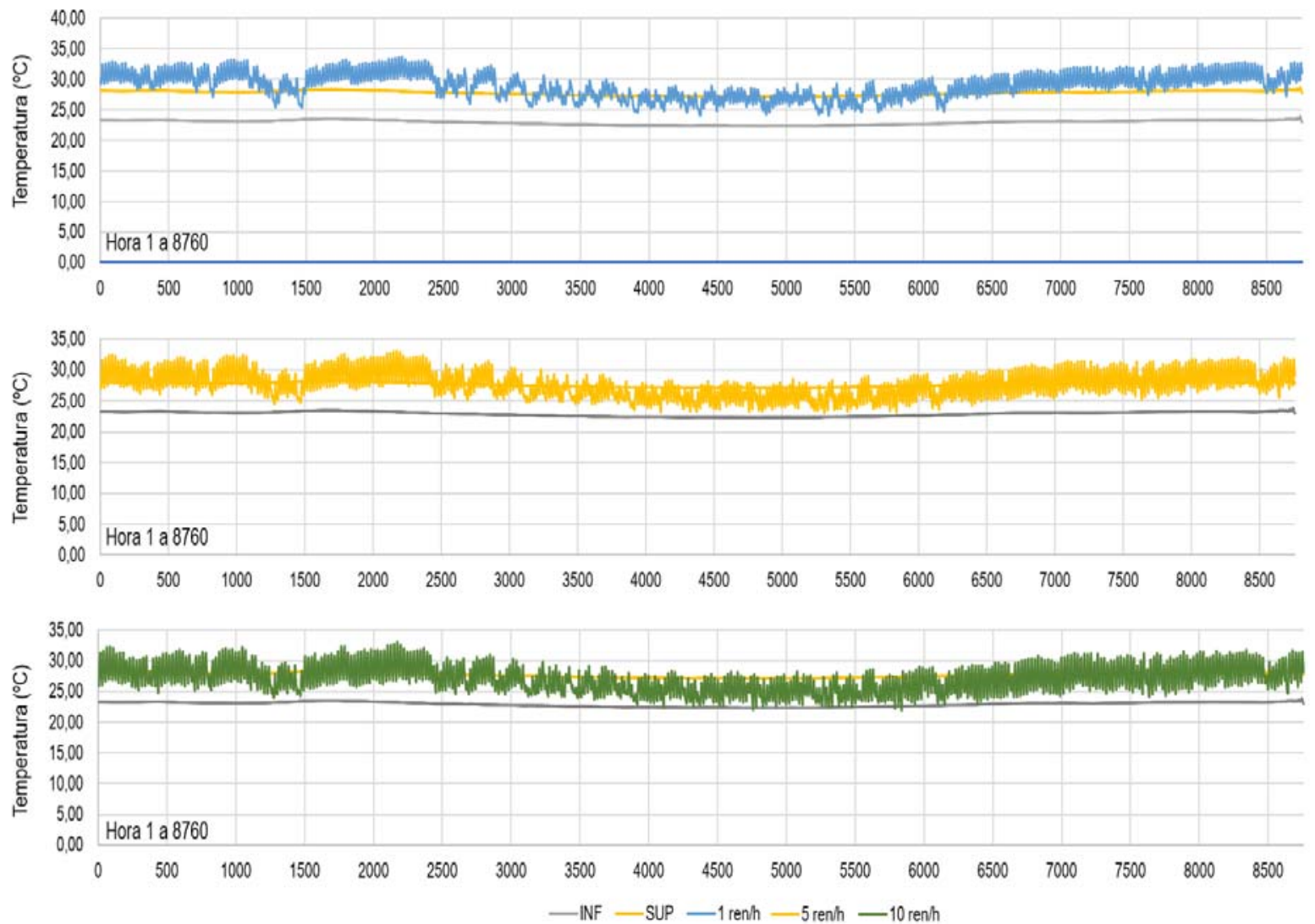

Fonte: O autor.

Observa-se aqui a influência da ventilação natural no conforto térmico dos usuários da edificação padrão, quanto maior o número de renovações do ar, maior o período em que a temperatura interna encontrase dentro dos limites da zona de conforto, evidenciando a possibilidade de uso destra estratégia passiva para condicionamento térmico e diminuindo assim a necessidade do uso de ar condicionado nestas habitações.

Esta constatação é importante para a documentação e estímulo da redução da demanda energética nas edificações e consequentemente o impacto no orçamento familiar desta parcela da população, possibilitando maiores benefícios na utilização do espaço habitado.

Ao verificar a influência das variáveis analisadas, no conforto térmico dos usuários, foi possível observar que a transmitância térmica promove uma maior influência quando se trata de uma configuração com uma renovação de ar por hora, não provocando uma alteração significativa neste parâmetro para os casos com cinco e dez renovações de ar por hora (Figura 12). Já a absortância térmica oferece uma maior influência no conforto térmico, o aumento desta variável torna os ambientes mais desconfortáveis em todos os casos analisados (Figura 13). 
Figura 12: Porcentagem de desconforto térmico em função da Transmitância para 1 ren/h, 5 ren/h e 10 ren/h.

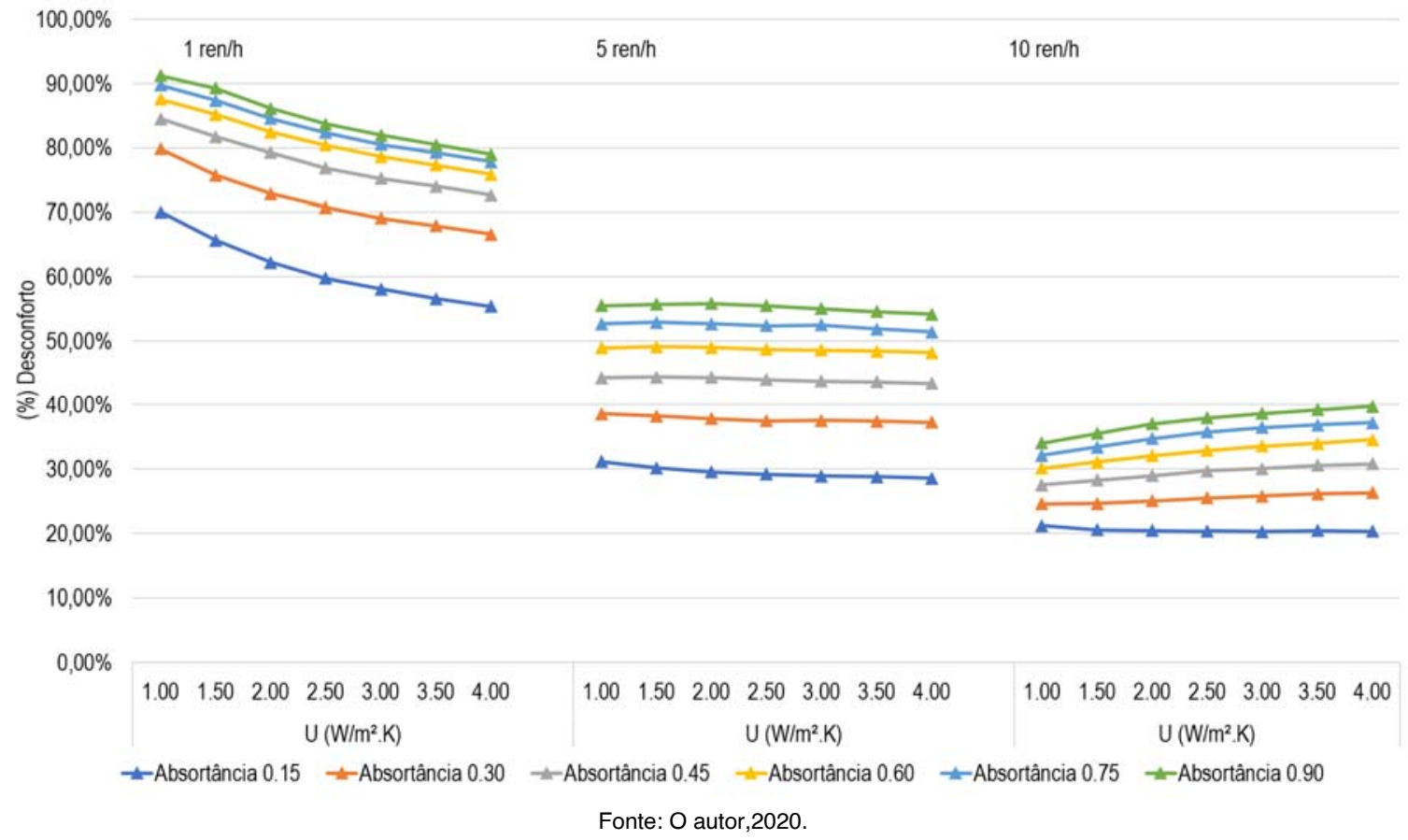

Figura 13: Porcentagem de desconforto térmico em função da Absortância para 1 ren/h, 5 ren/h e 10 ren/h.

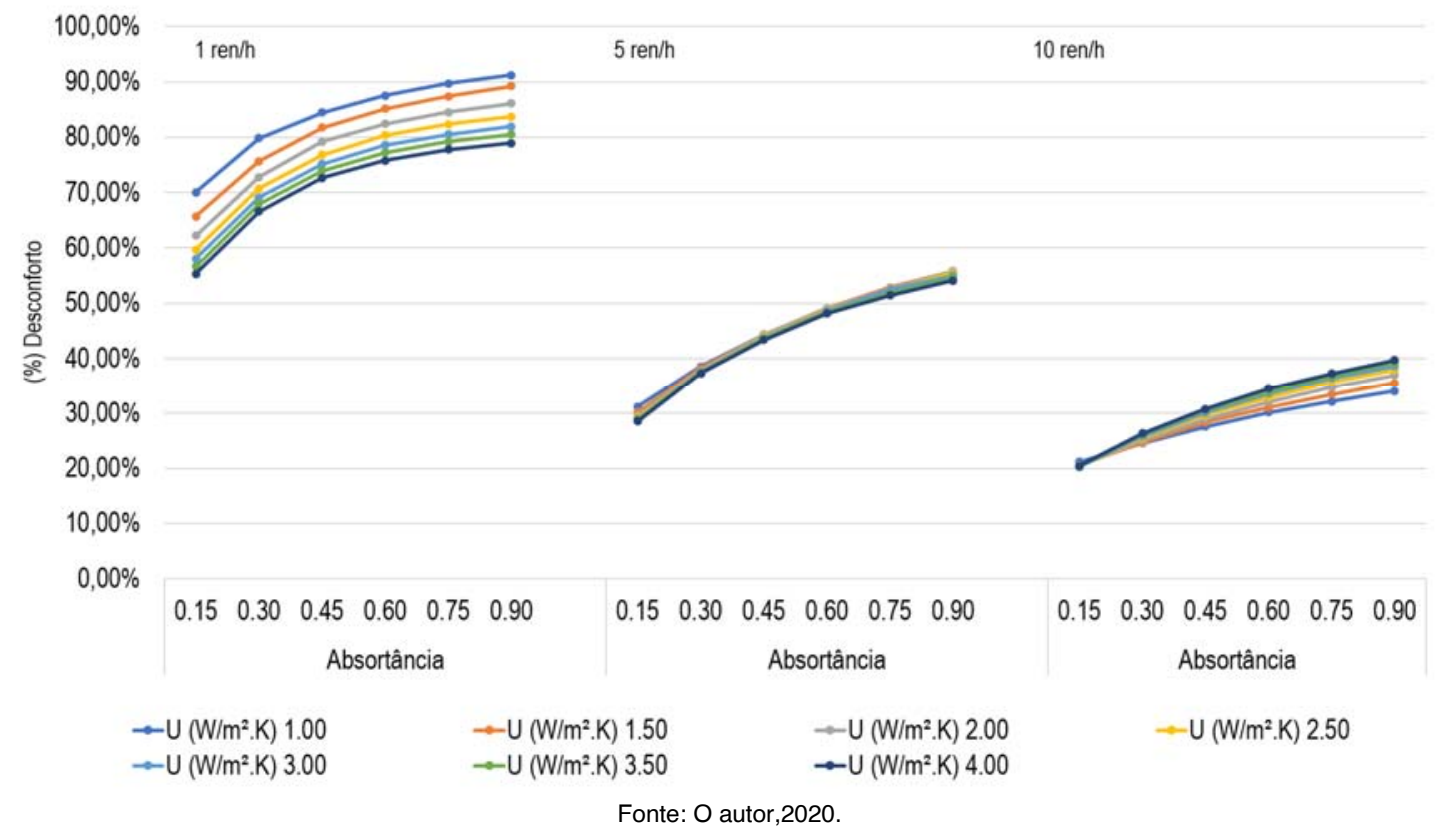

Na Figura 14, é possível comprovar esta constatação, tendo em vista que as curvas de tendências das médias para cada variável indicam o comportamento da mesma. No caso da transmitância térmica, esta tendência se deu de forma linear, decrescente para 01 e 05 renovações de ar por hora e crescente para 10 renovações de ar por hora, evidenciando o fator ventilação natural, capaz de suprir a falta de isolamento térmico no caso de climas como o de Maceió. Estas inclinações das retas, vale ressaltar que apresentam valores na ordem de $10^{(-2)}$ para $1 \mathrm{ren} / \mathrm{h}$ e $10^{(-3)}$ para $5 \mathrm{ren} / \mathrm{h}$ e $10 \mathrm{ren} / \mathrm{h}$, considerados baixos para um impacto no conforto térmico, quando comparado com seu investimento para implantação do isolamento térmico nas fachadas. Já para a absortância térmica, embora se observe uma tendência 
parabólica, esta curva apresenta-se sempre de forma crescente indicando um maior impacto no conforto térmico dos usuários a partir do aumento desta variável.

Figura 14: Tendências da porcentagem de desconforto térmico em função da transmitância (à esquerda) e da Absortância (à direita) para $1 \mathrm{ren} / \mathrm{h}, 5 \mathrm{ren} / \mathrm{h}$ e $10 \mathrm{ren} / \mathrm{h}$.
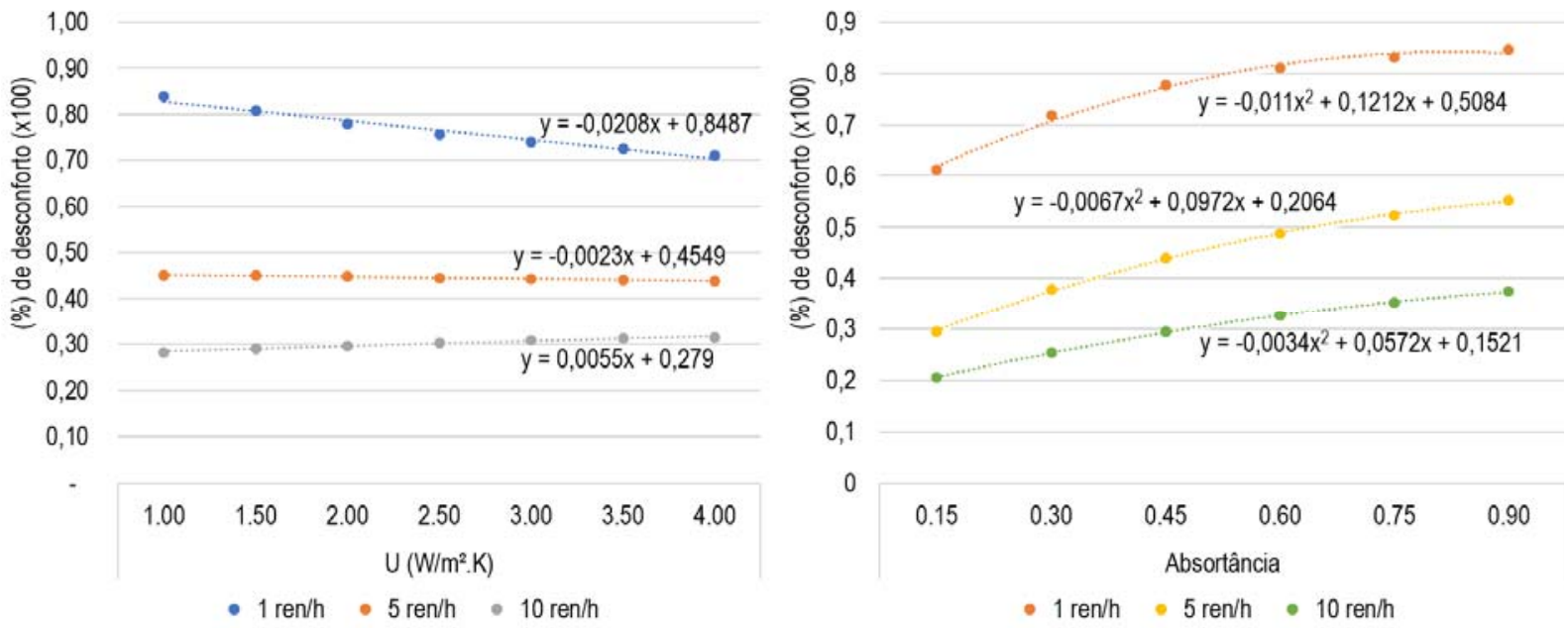

Fonte: O autor

É possível constatar também que a transmitância térmica promove uma maior influência no conforto térmico quando analisada no modelo com uma renovação de ar por hora, sem ventilação natural. Neste caso, o isolamento deve ser considerado quando não se utiliza ar condicionado nas edificações, no entanto, ao considerar a ventilação natural, o isolamento térmico parra a não influenciar de forma direta no comportamento térmico deste ambiente.

Para a absortância térmica, deve-se priorizar a utilização de "cores claras", com absortâncias abaixo de 0,45 , atingindo assim um percentual de desconforto abaixo de $43,5 \%$, valor considerado como base a partir dos dados climáticos plotados na zona de conforto com aceitabilidade de $90 \%$ para a cidade de Maceió.

Foi possível observar também que para a situação de 5 ren/h, o uso desta estratégia proporcionou menos conforto que alguns valores de absortância para uma ventilação maior (10 ren/h), apresentando-se como uma importante variável para o projeto de edificações que busquem o conforto dos usuários.

\section{Conclusões}

Pode-se afirmar a partir destas análises que a absortância apresenta maior influência na promoção do conforto térmico dos usuários para a cidade de Maceió, quando comparado ao impacto causado pelo isolamento térmico das fachadas, pois quanto maior o valor para esta variável, maior será o consumo energético caso exista a opção pelo uso de ar condicionado e maior será também o desconforto térmico ainda que se opte pelo uso da ventilação natural.

Esta constatação se torna importante em virtude de seu custo (apenas pintura) quando comparado com a adoção de sistemas de vedação vertical priorizando o isolamento térmico, com maiores custos para implantação, no entanto, deve-se considerar a manutenção deste acabamento ao longo do ciclo de vida útil da edificação.

A escolha pelo uso de sistema de condicionamento de ar para o controle da temperatura interna dos 
ambientes, pode promover um impacto significativo no orçamento familiar, principalmente quando se trata de usuários de habitações de interesse social, podendo atingir valores próximos a $R \$ 500,00$, o que é considerado elevado para esta parcela da população.

Vale ressaltar que este estudo não considerou variação de outras propriedades termofísicas deste sistema construtivo como capacidade térmica, calor específico e densidade, por se tratar de uma análise teórica, no entanto, estas propriedades devem ser levadas em consideração durante o processo de especificação de materiais para a envoltória.

Sugere-se para trabalhos futuros a análise da influência destas variáveis de forma paramétrica com o objetivo de identificar a propriedade termofísica que pode ser alterada com maior facilidade, gerando menor impacto no custo final da construção e de manutenção, visando a promoção de um maior período em conforto térmico nas edificações.

Deve-se também priorizar para a cidade de Maceió, o uso da ventilação natural, principalmente em habitações de interesse social, que foi objeto de estudo nesta pesquisa, pois foi comprovado que $o$ ar condicionado pode gerar um gasto excessivo e desnecessário com a promoção de conforto térmico, sensação que pode ser obtida ao utilizar baixa absortância associada à ventilação natural nas edificações.

Diante destes aspectos, este trabalho pretende contribuir para a discussão sobre as decisões projetuais e a disseminação do pensamento de que "quanto mais isolamento melhor" para o caso da cidade de Maceió, nem sempre deve ser uma prática a ser adotada.

\section{Referências}

ABNT, Associação Brasileira de Normas Técnicas. NBR 15220-03: Desempenho térmico de edificações Parte 3: Zoneamento bioclimático brasileiro e diretrizes construtivas para habitações unifamiliares de interesse social. Rio de Janeiro, 2005.

ABNT, Associação Brasileira de Normas Técnicas. NBR 15575: Edificações Habitacionais Desempenho: Parte 1: Requisitos Gerais. Rio de Janeiro, 2013.

AL-HOMOUD, M.S. The effectiveness of thermal insulation in different types of buildings in hot climates. Journal of Building Physics, vol27, p.235-247. 2004 doi https://doi.org/10.1177/1097196304038368

ALMEIDA, L. S. S. Influência de parâmetros físicos e geométricos no desempenho termoenergético de habitações unifamiliares. 2014. 133f. Dissertação (Mestrado em Engenharia Civil) - Universidade Federal de Santa Catarina, Florianópolis, 2014.

ALTERMAN, D, MOFFIET, T, HANDS, S, PAGE, A, LUO, C, MOGHTADERI, B, A concept fora potential metric to characterise the dynamic thermal performance of walls, Energy and Buildings $v 54$ p.52-60. 2012. doi https://doi.org/10.1016/j.enbuild.2012.08.006

ARSAL, Agência Reguladora de Serviços Públicos do Estado de Alagoas. Tarifas Baixa Tensão. site. sd. Disponível em: http://www.arsal.al.gov.br/tarifas/energia/tarifas-baixa-tensao Acesso em: 14 de junho de 2020.

ASHRAE - American Society of Heating, Refrigerating and Air-conditioning Engineers. ASHRAE.. Standard 55-2013Thermal Environmental Conditions for Human Occupancy. Atlanta, 2013.

ASHRAE, American Society of Heating, Refrigerating and Air-conditioning Engineers. ASHRAE 
Standard 140: standard method of test for the evaluation of building energy analysis computer programs. Atlanta, 2011.

BRASIL. Lei $\mathbf{n}^{\circ}$ 11.977, de 7 de julho de 2009. Brasília, DF: Subchefia para assuntos jurídicos, 7 jun. 2009. Disponível em: http://www.planalto.gov.br/ccivil_03/_Ato2007-2010/2009/Lei/L11977.htm. Acesso em: 15 mai. 2020.

CEF, Caixa Econômica Federal. Banco de Projetos de Habitação de Interesse Social. Disponível em: http://www.caixa.gov.br/Downloads/banco-projetos-projetos-

HIS/Casa_32,35m2_1_Dormit\%C3\%B3rio.zip . s/d. Acesso em: 07 de maio de 2020.

CHVATAL, Karin M Soares. Avaliação do procedimento simplificado da NBR 15575 para determinação do nível de desempenho térmico de habitações. In: Ambiente Construído. vol.14 no.4 Porto Alegre. 2014. doi https://doi.org/10.1590/S1678-86212014000400009

DEVGAN, S. JAIN, A. K. BHATTACHARJEE, B. Predetermined overall thermal transfer value coefficients for Composite, Hot-Dry and Warm-Humid climates. Energy and Buildings. Vol.42. 18411861. 2010. doi https://doi.org/10.1016/j.enbuild.2010.05.021

DORNELLES, K. A. Absortância solar de superfícies opacas: métodos de determinação e base de dados para tintas Látex Acrílica e PVA. 160 f. Tese (Doutorado em Engenharia Civil) - Faculdade de Engenharia Civil, Arquitetura e Urbanismo, Universidade Estadual de Campinas, Campinas, 2008.

FERREIRA, C. C., SOUZA, H. A. de, ASSIS, E. S. de. Discussão dos limites das propriedades térmicas dos fechamentos opacos segundo as normas de desempenho térmico brasileiras. Ambiente Construído, Porto Alegre, v. 17, n. 1, p. 183- 200, jan./mar. 2017. doi https://doi.org/10.1590/s167886212017000100131.

FRANK, T, Climate change impacts on building heating and cooling energy demand in Switzerland, Energy and Buildings Vol.37 1175-1185. 2005. doi https://doi.org/10.1016/j.enbuild.2005.06.019

GALLARDO, A. A. et al. Analysis and optimization of the thermal performance of social housing construction materials in Ecuador. PLEA 2016 - 32nd International Conference on Passive and Low Energy Architecture. Anais...Los Angeles: PLEA 2016.

INMETRO, Instituto Nacional de Metrologia e Qualidade Industrial. Regulamento Técnico da Qualidade para o Nível de Eficiência Energética de Edificações Residenciais (RTQ-R). Rio de Janeiro: INMETRO, 2012.

KALUA, A.; ZHAN, C.; CHANG, C.C. A review of green building advocacy in least developed countries. In Proceedings of the CIB W107 2014 International Conference, Lagos, Nigeria, 28-30 January 2014.

KALUA, Amos. Envelope Thermal Design Optimization for Urban Residential Buildings in Malawi. In: Buildings vol6, n13; 2016. doi:10.3390/buildings6020013

KOWALTOWSKI, D. C. C. K.; GRANJA, A. D. The concept of desired value as a stimulus for change in social housing in Brazil. Habitat International, v. 35, n. 3, p. 435-446, 2011. doi https://doi.org/10.1016/j.habitatint.2010.12.002

LAM, J.C. WAN, K.K.W. TSANG, C.L. YANG, L. Building energy efficiency in diferente climates, Energy Conversion and Management Vol.49 num.8 2354-2366, 2008. doi https://doi.org/10.1016/j.enconman.2008.01.013

LAMBERTS, R.; TRIANA, M. A. Levantamento do estado da arte: energia. São Paulo, 2007. 
Disponível em: <https://issuu.com/gcolombo/docs/levantamentodo estadodaarte_energia_94pg>. Acesso em: 22 set. 2019.

MASOSO, O.T. and GROBLER, L.J. A new and innovative look at anti-insulation behaviour in building energy consumption..Energy and Buildings. Volume 40, Issue 10, Pages 1889-1894 , 2008. doi https://doi.org/10.1016/j.enbuild.2008.04.013

MORENO, A. C. R.; MORAIS, I. S. DE; SOUZA, R. V. G. DE. Thermal performance of social housing a study based on brazilian regulations. 8th International Conference on Sustainability in Energy and Buildings. Anais...Turin, ITALY: Elsevier B.V., 2017. doi https://doi.org/10.1016/j.egypro.2017.03.013

PASSOS, I. C. da S. Clima e arquitetura habitacional em Alagoas: estratégias bioclimáticas para Maceió, Palmeira dos Índios e Pão de Açúcar. 2009. 173f. Dissertação (Mestrado em Arquitetura e Urbanismo: Dinâmicas do Espaço Habitado) - Universidade Federal de Alagoas. Faculdade de arquitetura e Urbanismo. Maceió, 2009.

PEDRINI, A. WESTPHAL, F.S. LAMBERTS R, A methodology for building energy modeling and calibration in warm climates, Building \& Environment Vol.37 903-912. 2002. doi https://doi.org/10.1016/S0360-1323(02)00051-3

PIRES, J. R. Investigação da viabilidade da redução do consumo de energia elétrica em edificações residenciais através da aplicação de soluções de conforto ambiental passivo. [s.l.] Universidade do Vale do Rio dos Sinos, 2013.

PMM, Prefeitura Municipal de Maceió. Lei Municipal n. 5.593, de 08 de fevereiro de 2007. Código de Urbanismo e Edificações de Maceió, Diretoria do Plano Diretor. Maceió. 2007.

$\mathrm{RADHI}, \mathrm{H}$. Can envelope codes reduce electricity and $\mathrm{CO} 2$ emissions in different types of buildings in the hot climate of Bahrain? Energy Vol.34 205-215. 2009. doi

https://doi.org/10.1016/j.energy.2008.12.006

RORIZ, M. ZBBR, versão 1.1. Universidade Federal de São Carlos, Programa de Pós-Graduação em construção Civil. 2004. Disponível em http://www.labeee.ufsc.br/software/zbbr.html acesso em 09 jun 2020.

RORIZ, Maurício. Arquivos Climáticos de Municípios Brasileiros. Texto para o Grupo de Trabalho sobre Conforto e Eficiência Energética de Edificações, São Carlos, 2012. disponível em: http://roriz.dominiotemporario.com/doc/Sobre_os_arquivos_EPW.pdf. Acesso em 02 Junho de 2020.

RORIZ, Maurício; CHVATAL, Karin Maria Soares; CAVALCANTI, Fernando Sá. Sistemas construtivos de baixa resistência térmica podem proporcionar mais conforto. Encontro Nacional de Conforto no Ambiente Construído. Anais.. Natal: [s.n.], 2009.

RUFINO, M. B. C. (Org.). Minha Casa... E a Cidade? Avaliação do Programa Minha Casa Minha Vida em seis estados Brasileiros. Rio de Janeiro: Letra Capital, 2015.

SORGATO, M. J.; MELO, A. P.; LAMBERTS, R. Análise do Método de Simulação de Desempenho Térmico da Norma NBR 15575. In: Encontro Nacional de Conforto no Ambiente Construído, 12. Brasília, 2013. Anais... Brasília: ANTAC, 2013.

TRIANA MONTES, M. A. Abordagem integrada no ciclo de vida de habitação de interesse social considerando mudanças climáticas. 2016. 473f. Tese (Doutorado em Engenharia Civil) Universidade Federal de Santa Catarina, Florianópolis, 2016. 
TRIANA, M. A.; LAMBERTS, R.; SASSI, P. Characterisation of representative building typologies for social housing projects in Brazil and its energy performance. Energy Policy, 87. December 2014, 2015.p.524-541. doi https://doi.org/10.1016/j.enpol.2015.08.041

UCLA, University of California, Los Angeles. Climate Consultant 6.0. Universidade da Califórnia, Los Angeles, EUA. 2016. Disponível em http://www.energy-design-tools.aud.ucla.edu acesso em 09 jun, 2020.

YIK, F.W.H., WAN, K.S.Y., An evaluation of the appropriateness of using overall thermal transfer value (OTTV) to regulate envelope energy performance of air-conditioned buildings, Energy Vol.30 41-71. 2005. doi https://doi.org/10.1016/j.energy.2004.03.001 